\title{
LA MUERTE DE UN GRAN POETA
}

\author{
Leonidas Morales \\ Universidad de Chile, Santiago de Chile, Chile \\ 1moralest@vtr.net
}

La muerte del poeta Nicanor Parra (23 de enero de 2018, a los 103 años) nos invita a preguntarnos por la índole y la trascendencia de la obra poética que deja. Intentaré aquí alguna respuesta. Advirtiendo sí de antemano que en una nota circunstancial como la presente, no hay lugar evidentemente para desarrollos críticos mayores. De manera pues que a la pregunta por la índole y la trascendencia de esta poesía, escrita a lo largo de muchos años, trataré de responder solo en términos generales, limitándome además a destacar aquellos planos de la obra de Parra que me parecen más pertinentes que otros.

Empezaría preguntándome por la materialidad significante de esta poesía, quiero decir, por la forma que adopta como lenguaje (en todos los niveles expresivos que confluyen en él). Esta forma es la de un tipo de poema con el que identificamos la poesía de Parra y que conocemos con el mismo nombre que le dio su autor: el de antipoema. El antipoema, en el orden de sus publicaciones, aparece primero en una antología: 13 poetas chilenos, de 1948 . Son tres títulos: "La trampa", "La víbora" y "Los vicios del mundo moderno". Los tres están incluidos en el libro posterior que marca la "consagración" del antipoema: Poemas y antipoemas, de 1954.

Los rasgos de identidad del antipoema son conocidos (al margen de la función que se les atribuya o de la interpretación textual que se haga de ellos). Para empezar, es propio de su verso la entonación relajada que invoca en el lector la proximidad del habla de todos los días. Otro tanto ocurre con el léxico, donde también es reconocible una palabra presente en las diversas esferas de la práctica ordinaria del lenguaje. Por otra parte, la voz que enuncia en el antipoema no oculta, no disfraza, no difumina ni mitifica su identidad. No se inviste de ningún prestigio, de ningún poder iluminado que la distancie del lector y la remita a un orden por encima de él. Por el contrario, es una voz cercana, a ratos 
familiar, que pareciera tener como domicilio uno en el mismo barrio del lector, o uno en que éste pueda al menos representárselo en el mundo cotidiano.

A estas marcas debemos agregar otra, una constitutiva de la enunciación misma, que cruza con su juego subversivo todo el espacio significante del antipoema, invisible pero perfectamente audible: el humor. Este humor nunca complaciente desarma las verdades absolutas, hace chocar o invierte los opuestos, afirma cuando niega, relativiza las categorías políticas o poéticas, pone en tela de juicio modelos y paradigmas instalados, ironiza lo obvio. En este sentido el antipoema se deja concebir, y sin esfuerzos, como un verdadero dispositivo de desconstrucción generalizada, dándole aquí a este término el sentido conceptualizado primero por Foucault y rediscutido más tarde por Agamben (7-31). No sería pensable el antipoema como dispositivo sin el humor: dentro del juego significante de sus distintos componentes, el humor cumple funciones estratégicas.

Sin duda, de los rasgos hasta aquí reseñados ya se infiere un tipo de poesía y un tipo de enunciante que no formaban parte de las prácticas de escritura de los poetas vigentes de habla hispana en las dos primeras décadas de la trayectoria del antipoema. Cito dos momentos textuales donde Parra, en su lenguaje paródico, pone en una relación de contraste, de oposición, palabras que metonímicamente apuntan al "poema" en boga y otras que están en línea con el antipoema insurgente. Uno, en "Advertencia al lector" de Poemas y antipoema, dice:

Según los doctores de la ley este libro no debiera publicarse:

La palabra arcoíris no aparece en él en ninguna parte,

Menos aún la palabra dolor,

La palabra Torcuato.

Sillas y mesas sí que figuran a granel,

¡Ataúdes! ¡útiles de escritorio!

Lo que me llena de orgullo

Porque, a mi modo de ver, el cielo se está cayendo a pedazos.

Y haciéndose cargo de la centralidad del gesto desconstructor del antipoema y de lo que él significaba en el contexto literario y poético histórico de su aparición, Parra cambia humorísticamente la modalidad del discurso y lo enuncia en los términos de un "manifiesto". En su poema Manifiesto del año 1963, lo anuncia de manera enfática, a la manera de una proclama:

Señoras y señores

Ésta es nuestra última palabra

-Nuestra primera y última palabra-

Los poetas bajaron del Olimpo. 
Un real "acontecimiento" se produce en la poesía de Parra de la década de 1970, no siempre destacado suficientemente, a pesar de la importancia que tiene para una lectura crítica. Comenzamos a entrar en su curso apenas reparamos en lo siguiente: en que si la estructura del antipoema es una forma, ésta no es en absoluto una forma estática, destinada solo a repetirse cada vez. Hoy, con toda su historia desplegada, vemos con claridad lo que al comienzo no era posible. ¿Qué? Que la lógica a la que respondía la verdad del antipoema como dispositivo desconstructor, tal como se desarrolla en los primeros libros (entre ellos, además de Poemas y antipoemas, desde luego Versos de salón, de 1962), cargaba consigo, de manera implícita, un determinado imperativo que solo podía cumplirse cabalmente mediante la transformación de la estructura del antipoema en el objeto mismo del proceso desconstructivo. Dicho en otras palabras: la estructura, o la forma, del antipoema tenía también a su vez que ser desconstruida. Usando palabras propias de los rituales de la religión, diríamos que el antipoema salva su verdad y la impone, ofreciéndose a sí mismo en "sacrificio". Como veremos más adelante, solo así podría dar lugar a alguna forma de "resurrección".

Dentro de la obra de Parra, son los Artefactos, de 1972, los que manifiestamente ejecutan este segundo paso de esta poesía, los que ponen en escena la producción del acontecimiento del que hablo. Para empezar, por lo demás de modo muy llamativo, de los Artefactos ha desaparecido el soporte tradicional del poema: la página, el libro. Lo que se nos entrega bajo el título de Artefactos es una caja pequeña, de cartón. En su interior, sustituyendo a las páginas, se acumulan tarjetas postales formando un conjunto numeroso. Cada una de ellas, en su dorso, reproduce el diseño de las viejas tarjetas postales, pero ahora "intervenido". Arriba:

\title{
TARJETA POSTAL POST CARD
}

Abajo, a la izquierda:

\author{
ARTEFACTOS \\ HANDYWORKS \\ OUVRAGES MECANIQUES \\ APPARATY
}

\section{(C) by Nicanor Parra}

En la cara del frente va un texto. Pero el código verbal pierde aquí toda hegemonía y lo vemos por el contrario compartir el espacio frontal de la tarjeta con el código visual del dibujo, rasgo éste, el de la visualidad, trabajado por Parra de modo recurrente en su obra. Sin embargo, en esta ocasión los dibujos no son de Parra sino del prestigioso diseñador, diagramador y dibujante chileno Guillermo Tejeda. Están incorporados sin embargo al espacio significante: funcionan como una suerte de espejo cuya imagen es siempre 
funcional al texto, a su literalidad y a su humor. Por ejemplo, en uno de los artefactos aparece el siguiente texto: "LA MUERTE / Es un hábito colectivo". Arriba y al fondo el dibujo: un grupo de cadáveres que avanzan en bicicleta, atropellándose.

En resumen, los artefactos reiteran frente al lector la "explosión" del antipoema, su desintegración, incluyendo el soporte de su letra. De la voz de lo que era el personaje de la enunciación del antipoema solo quedan las huellas de su desaparición: fragmentos de voz que exhibiendo su condición se suceden veloces uno tras otro ${ }^{2}$.

Como lector crítico de la poesía de Parra, he planteado más de una vez, y la repito aquí, mi tesis de que los dos libros publicados a fines de la década de 1970, Sermones y prédicas del Cristo de Elqui, de 1977, y Nuevos sermones y prédicas del Cristo de Elqui, de 1979, representan exactamente un "post": lo que ha quedado, o lo que es posible, después de la desconstrucción del propio antipoema. Es cierto, vuelve con ellos el soporte tradicional de la escritura: la página y el libro. Regresa incluso un principio de "relato" luego de su fragmentación radical. Pero este "regreso" no es en verdad un regreso. En último término nada regresa o vuelve propiamente. Lo que en verdad encontramos en estos dos libros es el paisaje del "día después": un personaje ya enteramente destituido, habitante de un espacio fantasmal o fantasmagórico, enunciador de una palabra "débil" que ni siquiera ella misma parece esperar crédito alguno. Una palabra sin embargo que ocupa exactamente el lugar que le corresponde dentro de la "historia" reseñada del antipoema, es decir, la que va de 1954 a 1979. Es en ese período donde, desde mi punto de vista, toma cuerpo y se resuelve el gran aporte de Nicanor Parra a la poesía en lengua española, y dentro de ella, en particular a la poesía nuestra, la chilena.

Ahora bien, en cuanto poesía moderna, la de Parra no puede sino estar condicionada históricamente . Quiero decir que hay en el estado histórico de la modernidad dentro del cual se produce o genera la poesía de Parra, determinados hechos que la hacen posible o la mediatizan. En este sentido, es importante la posición de Parra (de su poesía) frente a las vanguardias históricas. Si bien asume el gesto rupturista de las vanguardias ante la "institución arte", en particular el de una vanguardia como el dadaísmo, que liquida la noción de arte tradicional sustituyendo la idea de objetos "creados" por la de objetos "encontrados", como el urinario de Duchamp, no hace suya en cambio la dimensión revolucionaria y utópica vanguardista, tan central en el surrealismo: devolver el arte a la vida cotidiana, pero dentro de otra sociedad, no la capitalista. Ya en la década de 1940 esta dimensión utópica iniciaba su declive, y su inactualidad es justamente un supuesto

$2 \quad$ Sobre qué sea el "artefacto", su lógica, el modo en que opera sobre el lector, Parra ha hecho comentarios de interés en mi libro Conversaciones con Nicanor Parra. $4^{\mathrm{a}}$ edición. Santiago, Ediciones Universidad Diego Portales, 2013. 78-90. 
general de la poesía de Parra. Y si pudiéramos de pronto intuir su presencia en ella, solo lo será a título de objeto desconstruido.

La etapa del capitalismo paralela al desarrollo de la antipoesía, le aportará a ésta su marco político (y cultural). A contar del fin de la Segunda Guerra, el eje del poder político comienza a desplazarse desde Europa a Estados Unidos donde, ya en la década de 1940, según el testimonio de Adorno y Horkheimer, exiliados políticos del nazismo, en su Dialéctica de la Ilustración ${ }^{3}$, aparece configurada una vida cotidiana regida por los medios de comunicación (cine, radio, prensa) y por la cultura convertida en "industria" de la entretención y el consumo. La consolidación de Estados Unidos como eje del poder político será también, al mismo tiempo, su consolidación como representante protagonista del mundo capitalista frente a la Unión Soviética como representante del mundo socialista. La antipoesía no toma partido explícito en este ajedrez político de polos excluyentes, pero tampoco se abstiene: pone en juego su dispositivo para desconstruir los absolutos políticos.

Estados Unidos será el conductor principal del proceso que se precipita desde la década de 1980: el de la globalización de la sociedad capitalista, es decir, de la sociedad del mercado y el consumo, de la hegemonía de los medios y, por supuesto, de la "industria" de la cultura. Y junto con ella, la "globalización" del inglés como lengua del comercio, del turismo y, en general, como lengua insustituible de la comunicación universal. El reinado del francés desde el siglo XIX hasta las primeras décadas del XX, había pues terminado. El sociólogo brasileño Fernando Ortiz ${ }^{4}$ estudia cuidadosamente la trayectoria del inglés desde la expansión neocolonialista del siglo XIX hasta el nuevo estatus que adquiere con la globalización, uno que compromete, más allá de los medios, la educación en todos sus niveles, y la investigación en los espacios académicos.

Parra no asistió a todos estos cambios políticos y culturales, ni los procesó en su poesía, solo desde la distancia latinoamericana de un país remoto (Chile), sino también en la frecuentación de los espacios sociales y culturales originarios desde donde tales cambios operaban. Como físico y matemático que era, fue becado en 1943 para hacer estudios avanzados de Mecánica en Brown Universitty, Estados Unidos. Estuvo hasta 1945. En 1949, también becado, viaja a Inglaterra a estudiar Cosmología en la Universidad de Oxford durante dos años. En ambos países abre su campo de lector a la poesía en lengua inglesa. En Estados Unidos, a la de Whitman, y en Inglaterra, a la de Blake, Eliot, Pound. También a la narrativa de Kafka. Esos años de inmersión en la vida cotidiana, y en la lengua de la misma, de dos países decisivos dentro del rumbo de la modernidad y el capitalismo del siglo XX, no son por cierto ajenos a la antipoesía. Tampoco lo es, ni mucho menos, el tipo de pensamiento contemporáneo al que Parra accede desde sus

3 La traducción española de la edición alemana es de Juan José Sánchez. Madrid: Editorial Trotta, 1994.

$4 \quad$ La supremacía del inglés en las ciencias sociales. Traducción del portugués Teresa Beatriz Arijón. Buenos Aires: Siglo XXI Editores, 2009. 
estudios científicos avanzados, uno en que la ciencia encuentra en el lenguaje ordinario el objeto de una nueva reflexión y de apertura a un nuevo saber.

Para ir cerrando esta nota, me detendré un momento en la recepción de la antipoesía. Empiezo trasladando el enfoque hacia la poesía chilena vigente en las décadas de 1940 y 1950, cuando la antipoesía irrumpe. Los nombres con los que asociamos esa poesía son de sobra conocidos: Huidobro, Neruda, De Rokha. El "modelo" que la condiciona no ha abandonado la utopía vanguardista. La voz que enuncia en sus poemas sigue siendo una voz privilegiada y casi mitológica, de iluminado o portavoz de sueños colectivos. La palabra está desde luego a la altura de la voz que la enuncia: también singular, distinta, única. Es evidente que la antipoesía de Parra venía a ocupar, en un contexto semejante, un lugar abiertamente incómodo (Algunas lecturas incluso "localizan" ligeramente el significado del "anti", reduciéndolo a ser una suerte de anti Neruda). Pero estaba llamada no obstante a conquistar una posición protagónica, inevitable a la luz del estado y la dirección de la modernidad que la condicionaba. Hoy es inconcebible sin ella la historia posterior de la poesía chilena.

Al comienzo, década de 1950, tuvo una recepción dubitativa y desigual. El poeta Enrique Lihn está entre los que percibieron rápidamente su importancia. Pero pronto, desde la década siguiente, la recepción se hará cada vez más amplia y críticamente más intensa y minuciosa en su análisis. Sobre todo a contar de la década del 80 y hasta el presente, se multiplican, al mismo tiempo que su difusión, los estudios, en diferentes lenguas, que resaltan el aporte revolucionario de la antipoesía a la poesía en lengua española. Paralelamente, como efecto de ese reconocimiento, vienen las distinciones académicas, invitaciones a centros culturales y académicos, y por supuesto los premios, empezando con el Premio Nacional de Literatura Chilena, otorgado en 1969. Destaco algunos otros: Premio Juan Rulfo, México 1991. Premio Reina Sofía de Poesía Iberoamericana, España 2001. Premio Miguel de Cervantes, España 2011. Premio Iberoamericano de Poesía Pablo Neruda, Chile 2012. A los premios hay que sumar cuatro postulaciones al Nobel por parte de instituciones chilenas y extranjeras.

En Chile desde luego estos estudios y publicaciones, como libro o en revista, no son pocos. Son sí de muy diverso interés. Hay sin embargo algunos de lectura obligada, imprescindibles en cualquier balance de la recepción de Nicanor Parra. Entre ellos, particularmente gratificante como lenguaje y análisis textual, crítico e histórico, es el libro de Federico Schopf, Del vanguardismo a la antipoesía: ensayos sobre la poesía en Chile. Publicado primero en Italia en 1986, su edición chilena es del 2000. El título es explícito respecto de su objeto de investigación: Schopf estudia, con un aparato bibliográfico, teórico y crítico, que le permite fundamentar ampliamente su análisis, el fenómeno de las vanguardias históricas, sus tesis, sus prácticas, el modo en que se proyectan en la poesía chilena de las décadas del 20 y del 30 (Huidobro, Neruda), y, ya 
en el horizonte de la postvanguardia o del "final" de las vanguardias, la forma específica en que se resuelven, en la antipoesía de Parra.

Hay, en el caso de Parra, una cierta clase de recepción que no debería pasarse por alto por la confusión crítica que introduce. No es otra del mundo académico, sino una asociada a los medios de comunicación. En efecto, la antipoesía, desde hacía un largo tiempo, había venido convirtiéndose en el componente de un fenómeno mediático cuyo centro era el mismo Parra, al que éste contribuía con el histrionismo de su personalidad, espectacularizando el humor de ciertos textos suyos, pero también anecdotizado por su larga vida y potenciado por el prestigio nacional e internacional que lo acompañaba. De esta manera, los medios terminaron cumpliendo con su función dentro de la sociedad capitalista: reemplazando las coordenadas de una evaluación crítica discriminadora y verdaderamente comprensiva, por otras que se resuelven en definitiva en celebraciones, en la reiteración de tópicos instalados, en juicios cerrados, sin análisis. Era necesario dar cuenta de este fenómeno no solo como advertencia ante las confusiones que introduce, sino porque representa también un tema que reclama un estudio exploratorio de las relaciones existentes entre él y la poesía de Parra escrita después de los Sermones, es decir, desde la década de 1980.

\section{BIBLIOGRAFÍA}

Agamben Giorgio. ¿Qué es un dispositivo? Traducción de Mercedes Ruvituso. Buenos Aires: Adriana Hidalgo Editora, 2016.

Horkheimer Marx y Theodor Adorno. Dialéctica de la Ilustración. Traducción de Juan José Sánchez. Madrid: Editorial Trotta, 1994.

Morales T. Leonidas. Conversaciones con Nicanor Parra. Santiago: Editorial Universitaria, 1991.

Ortiz Fernando. La supremacía del inglés en las ciencias sociales. Traducción de Teresa

Beatriz Arijón. Buenos Aires: Siglo XXI Editores, 2009.

Parra Nicanor. Poemas y antipoemas. Santiago: Editorial Nascimento, 1954.

Versos de salón. Santiago: Editorial Nascimento, 1962.

Manifiesto. Santiago: Editorial Nascimento, 1963.

Artefactos. Santiago: Ediciones Nueva Universidad, Universidad Católica de Chile,

Vicerrectoría de Comunicaciones, 1972.

Sermones y prédicas del Cristo de Elqui. Santiago: Galería Época, 1977.

Nuevos Sermones y prédicas del Cristo de Elqui. Valparaíso: Ediciones Ganymedes, 1979.

Schopf, Federico. Del vanguardismo a la antipoesía. Santiago: Editorial LOM, 2000.

Zambelli Hugo (Ed.). 13 poetas chilenos. Valparaíso: Imprenta Roma, 1948. 